\title{
Molecular origins of fast and selective gas transport in pentiptycene-containing polyimide membranes and their physical aging behavior
}

Shuangjiang Luo, ${ }^{\dagger}$ Jennifer R. Wiegand, ${ }^{\dagger}$ Peiyuan Gao, ${ }^{\ddagger}$ Cara M. Doherty, ${ }^{\S}$ Anita J. Hill, ${ }^{\S}$ Ruilan $\mathrm{Guo}^{\dagger} *$

${ }^{\dagger}$ Department of Chemical and Biomolecular Engineering, University of Notre Dame, Notre Dame, IN 46556, United States

${ }^{\ddagger}$ Beijing National Laboratory for Molecular Sciences, Institute of Chemistry, Chinese Academy of Sciences, Beijing 100190, China

${ }^{\S}$ The Commonwealth Scientific and Industrial Research Organization (CSIRO) Manufacturing, Private Bag 10, Clayton South, Victoria 3169, Australia

* Corresponding author: +1-574-631-3453 (tel), +1-574-631-8366 (fax), rguo@nd.edu

KEYWORDS : pentiptycene; polyimides; gas separation membrane; bimodal microporosity; physical aging

ABSTRACT: This paper reports comprehensive characterization and detailed analyses of microporous structure and fundamental gas transport properties for a series of new pentiptycene-containing polyimide gas separation membranes prepared from custom-synthesized pentiptycene-based diamines and 4,4'-hexafluoroisopropylidene bisphthalic dianhydride (6FDA) to identify the molecular origins for fast and selective gas transport. Both experimental characterizations of inter-chain spacing and microporosity and molecular modeling analysis of chain conformations and rigidity suggested that rigid H-shape pentiptycene units effectively disrupted chain packing, resulting in large fractional free volume and consequent high gas permeabilities in these membranes. Atomic-level detection of free volume architecture by positron annihilation lifetime spectroscopy (PALS) analysis revealed a bimodal microcavity size distribution with cavity sizes of $d_{4} \sim 7-8 \AA$ and $d_{3} \sim 3-4 \AA$ in this series of membranes. The microcavity size and size distribution were found to be sensitively affected by the substituent groups in the pentiptycene monomer structure based on the mechanism of "partial filling" of internal molecular cavities defined by the shape of pentiptycene units. Analysis of fundamental gas transport properties in terms of diffusivity $(D)$ and solubility $(S)$ coefficients demonstrated that size sieving mechanism 
(diffusivity contribution) dominates the gas transport in these polymers and bimodal microcavity size distribution with ultrafine microporosity is responsible for the excellent $\mathrm{H}_{2}$-related gas separation performance. Superior resistance against physical aging was observed for these high-free-volume polymers, which is ascribed to the stable, configuration-induced microcavity structure constructed by the rigid pentiptycene units. 


\section{Introduction}

The use of polymeric membranes for gas separation lends itself to a variety of important industrial applications, such as hydrogen recovery, air separation, natural gas sweetening and carbon dioxide capture, etc., due to their energy efficiency, cost-effectiveness and ease of operation when compared to some traditional separation processes.[1-5] Generally, ideal gas separation membranes should exhibit high permeability in order to reduce the membrane area and capital cost, as well as high gas selectivity in order to achieve high separation efficiency and gas purity. However, polymeric gas separation membrane materials are always challenged by an inherent tradeoff between permeability and selectivity, as defined by the empirical Robeson's upper bound.[6, 7] This permeability-selectivity tradeoff can be ascribed largely to the limited amount of microcavities and undesired cavity size distribution in the membranes; thus, there is much interest currently in the fabrication of novel polymeric materials exhibiting microporosity with gas transport properties close to or even beyond the upper bounds.[5, 8-11]

Polyimides are among the most studied polymeric materials for membrane gas separation because of their excellent mechanical properties, high thermal and chemical resistance, good solution-processability, and more importantly, high gas selectivities.[1-3, 12] However, gas permeabilities of most common polyimides are relatively low, which limits their practical applications in large-scale gas separation. Therefore, many recent efforts have focused on developing novel polyimide structures with high fractional free volume (FFV) and high microporosity to enable ultrafast gas transport. A notable macromolecular strategy is to introduce bulky building blocks and/or highly contorted linkages into polyimide backbones to effectively disrupt chain packing leading to (ultra)microporous polymer membranes with large fractional free volume.[13-19] For instance, rigid and bulky spirobifluorene moieties,[16-18] as well as pendent phenyl structures,[19] were incorporated to inhibit tight chain packing and increase the fractional free volume leading to improved gas permeability. More recently, polyimides with intrinsic microporosity (PIM-PIs)[10, 20-23] and polyimides incorporating Tröger's base[24, 25] were fabricated, both of which integrated the merits of microporous PIMs and polyimides to achieve high gas permeabilities. However, the 
improvement of gas permeability in these novel polyimides was always accompanied by a decrease in selectivity. Thus, novel structural elements allowing precise control of both the microcavity size and size distribution are highly desired to unite high gas permeabilities with high selectivities.

We recently reported the synthesis and characterization of a new series of polyimides prepared from pentiptycene-based diamines and 4,4'-hexafluoroisopropylidene bisphthalic dianhydride (6FDA) as gas separation membranes (Figure 1a).[26] The novelty of this macromolecular design lies in incorporation of bulky, shape-persistent pentiptycene-derived structural units with intrinsic “internal microcavities” into polyimide backbone structures to exquisitely tune membrane's transport properties. In this previous report focusing on monomer/polymer synthesis and characterization, preliminary gas transport properties (i.e. permeabilities and selectivities) were examined to demonstrate the potential of these novel materials as gas separation membranes which actually showed very promising combinations of high gas permeability and selectivity close to the Robeson's upper bound.[26] However, the detailed microscopic chain packing structures, microporosity, free volume size distribution, chain rigidity, fundamental gas transport properties (i.e. diffusivity and solubility), as well as physical aging behavior, were not fully explored for these new materials. Therefore it is of great scientific importance to conduct comprehensive examination of these properties to provide an accurate picture of the gas transport pathway in these novel membranes and establish fundamental structure-property relationship as useful guidance for novel membrane materials design. In this study, we report the fundamental analysis of chain packing structures and free volume architecture (size and size distribution) of these newly-developed pentiptycene-containing polyimide membranes along with detailed analysis of gas transport properties in terms of diffusivity and solubility contribution. The aim of this work is to explore the molecular origins of fast and selective gas transport in these pentiptycene-containing polyimide membranes. A suite of characterization techniques coupled with molecular modeling are applied to provide profound understanding of fundamental correlation between microscopic structures and macroscopic gas transport properties and physical aging behavior of this new series of polymers. 


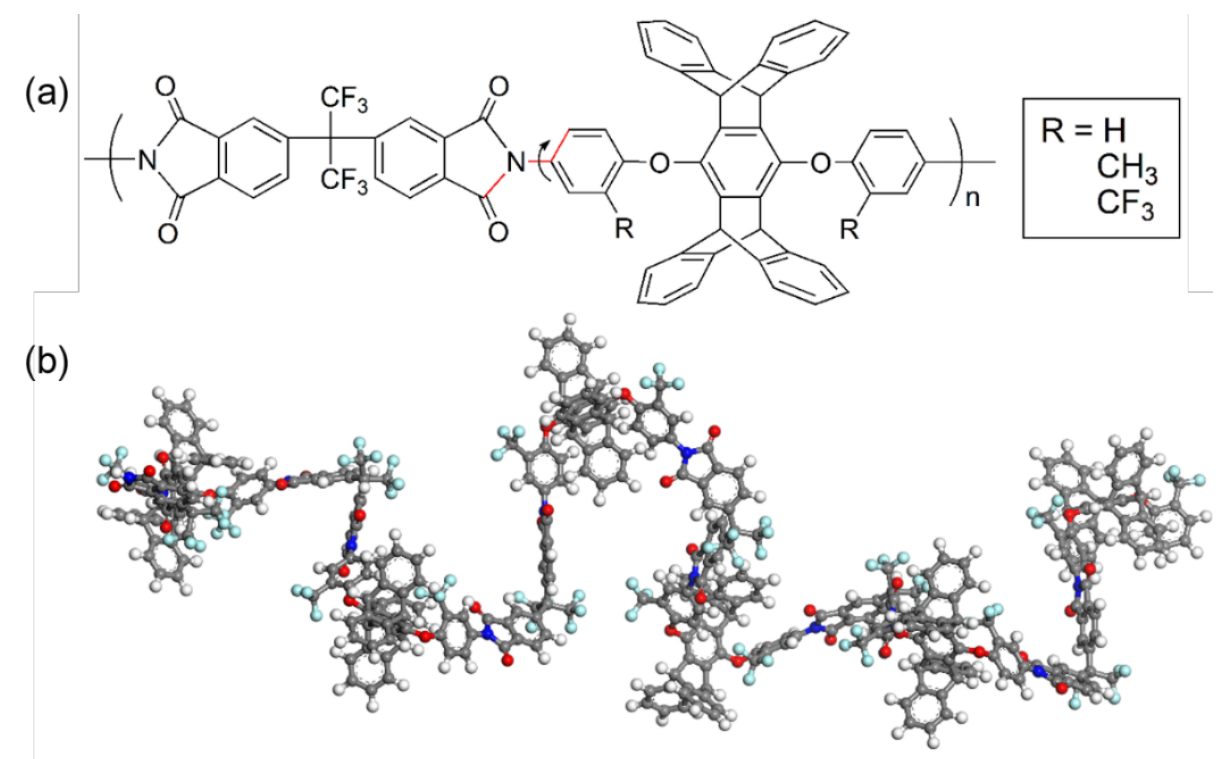

Fig. 1. (a) Chemical structures of 6FDA-pentiptycene polyimides; (b) energy-minimized conformational structure of a 6FDA-PPDA $\left(\mathrm{CF}_{3}\right)$ segment of six repeating units. Dihedral angle distributions of highlighted bonds were simulated.

\section{Experimental}

\subsection{Materials and film preparation}

The synthesis of pentiptycene-containing polyimides was reported in our previous study,[26] and the corresponding dense membranes were prepared by the solution casting method. Dimethylacetamide (DMAc) solution containing $~ 7 \%\left(\mathrm{w} / \mathrm{v}, \mathrm{g} \cdot \mathrm{mL}^{-1}\right)$ polymer were filtered through a $0.45 \mu \mathrm{m}$ PTFE filter and cast onto clean and leveled glass plates. The solution was heated under an infra-red lamp (Staco Energy Products Co., 120 V) at around 60 ${ }^{\circ} \mathrm{C}$ overnight to slowly evaporate the solvent, and clear, isotropic films were formed. The obtained films were dried at $140{ }^{\circ} \mathrm{C}$ in a vacuum oven for $16 \mathrm{~h}$, soaked in methanol for $24 \mathrm{~h}$ to remove residual casting solvent, and further dried at $140{ }^{\circ} \mathrm{C}$ under vacuum for another $24 \mathrm{~h}$. Complete removal of the casting solvent was verified using thermal-gravimetric analysis (TGA, TA Instrument, Q-500). Film thickness (in the range of 40-80 $\mu \mathrm{m}$ ) was measured using a digital micrometer, and the effective area of each film for permeation tests was determined by digitally analyzing the scanned images of the film obtained with a scanner (LiDE120, Canon) using ImageJ software. Long-term physical aging of the membranes was conducted by storing the films in sealed plastic dishes at ambient conditions for predetermined amount of days and the films were dried at $150{ }^{\circ} \mathrm{C}$ for $16 \mathrm{~h}$ before the pure gas 
permeation tests.

\subsection{Characterization methods}

Wide angle X-ray diffraction (WAXD) spectra were recorded in the reflection mode at room temperature using a D8 Advance Davinci diffractometer with $\mathrm{Cu} \mathrm{K} \alpha$ radiation (wavelength $\lambda=1.5418 \AA$ ) operated at $40 \mathrm{~mA}$ and $40 \mathrm{kV}$. The scan speed and step size were 7.5 second per step and $0.02^{\circ}$ per step, respectively. The $d$-spacing values were calculated from the diffraction peak maxima through Bragg's equation.

Positron annihilation lifetime spectroscopy (PALS) was performed under vacuum $\left(1 \times 10^{-5}\right.$ Torr) at room temperature using an EG\&G Ortec fast-fast coincidence timing system to investigate the size and relative distribution of free volume elements within the polyimide films. Polymer films were cut into $1 \times 1 \mathrm{~cm}$ pieces and stacked to a thickness of $2 \mathrm{~mm}$ on either side of the positron source $\left(1.5 \times 10^{6} \mathrm{~Bq}\right.$ of ${ }^{22} \mathrm{NaCl}$ sealed in a Mylar envelope). Each sample consisted five files of $4.5 \times 10^{6}$ integrated counts. The obtained raw data were analyzed using LT v9 software[27] using a source correction (1.609 ns and 4.002\%) and modeled as the sum of four components. The first two components were attributed to the para-positronium self-annihilation and the free annihilation. The last two components were due to ortho-positronium (o-Ps) decay in the free volume elements of the films. The size of free volume elements was calculated using the Tao-Eldrup equation:[28, 29]

$$
\tau=\frac{1}{2}\left[1-\frac{R}{R_{0}}+\frac{1}{2 \pi} \sin \left(\frac{2 \pi R}{R_{0}}\right)\right]
$$

where $\tau$ is the lifetime, $R$ is the radius of the pores and $R_{0}=R+\Delta R$ is the radius of potential well, where $\Delta R$ was determined to be $1.66 \AA$ based on the thickness of the electron layer within the potential well. The cavity size distributions were analyzed using PAScual software.[30]

Pure gas permeabilities of $\mathrm{H}_{2}, \mathrm{CH}_{4}, \mathrm{~N}_{2}, \mathrm{O}_{2}$ and $\mathrm{CO}_{2}$ were determined at $35{ }^{\circ} \mathrm{C}$ using the constant-volume variable-pressure method.[31] All membranes were degassed on both feed and downstream sides under high vacuum at $35{ }^{\circ} \mathrm{C}$ overnight before permeation tests. Pure gas was then fed to maintain predetermined upstream pressures (i.e., 3.0, 6.4, 9.8, 13.0 and $16.6 \mathrm{~atm})$, and the increase in downstream pressure over time was recorded with a MKS Baratron transducer. Gas permeabilities were calculated based on the steady-state rate of 
pressure increase as follows:

$P=10^{10} \frac{V_{d} l}{p_{\text {up }} T R A}\left[\left(\frac{d p}{d t}\right)_{s s}-\left(\frac{d p}{d t}\right)_{\text {leak }}\right]$

where $P$ (Barrer, 1 Barrer $=10^{-10} \mathrm{~cm}^{3}(\mathrm{STP}) \cdot \mathrm{cm} / \mathrm{cm}^{2} \cdot \mathrm{s}^{\cdot} \mathrm{cmHg}$ ) is the gas permeability, $V_{d}$ is the calibrated downstream volume $\left(\mathrm{cm}^{3}\right), l$ is the film thickness $(\mathrm{cm}), p_{u p}$ is the upstream pressure (cmHg), $T$ is the test temperature $(308.15 \mathrm{~K}), R$ is the gas constant $(0.278$ $\left.\mathrm{cm}^{3} \cdot \mathrm{cmHg} / \mathrm{cm}^{3}(\mathrm{STP}) \cdot \mathrm{K}\right), A$ is the effective film area $\left(\mathrm{cm}^{2}\right),(\mathrm{dp} / \mathrm{d} t)_{\mathrm{ss}}$ and $(\mathrm{d} p / \mathrm{d} t)_{\text {leak }}$ are the steady-state pressure increment in downstream due to permeation and the leak rate of the system (cmHg/s), respectively. The ideal selectivity $\left(\alpha_{A / B}\right)$ of two different gases $A$ and $B$ was defined as the ratio of pure gas permeabilities of the two gases:

$$
\alpha_{A / B} \equiv \frac{P_{A}}{P_{B}}
$$

The apparent diffusion coefficients $D\left(\mathrm{~cm}^{2} \cdot \mathrm{s}^{-1}\right)$ were calculated from the time-lag method using the following equation:[31]

$$
D=\frac{l^{2}}{6 \theta}
$$

Where $l$ is the film thickness $(\mathrm{cm})$ and $\theta$ is the lag time (s). The minimum limit of $D$ was estimated for $\mathrm{H}_{2}$ due to its very short lag time. The solubility coefficient ( $S$, $\left.\mathrm{cm}^{3}(\mathrm{STP}) / \mathrm{cm}^{3} \cdot \mathrm{atm}\right)$ was calculated based on solution-diffusion model via: $S=P / D$.

\subsection{Molecular modeling}

Modeling of the imide bond dihedral angles was done in Accelrys Materials Studio. Chain segments of pentiptycene-containing polyimides with six repeating units were fabricated, and the imide bond dihedral angles (Figure 1) were varied cumulatively from - $180^{\circ}$ to $+180^{\circ}$ using the Conformer module. Energy minimizations of all conformers were implemented with the Discover module (COMPASS force filed, Smart algorithm), and the energy barrier profiles of the dihedral angles were calculated and normalized relative to the lowest energy attained over the $360^{\circ}$ range.

\section{Results and discussion}

\subsection{Molecular chain packing and free volume architecture characterization}


Polymer chain packing is important for understanding gas transport in dense membranes because the inter-chain spacing, known as $d$-spacing, values are usually perceived to represent the distance between polymer segments, which has been shown to be closely related to fractional free volume (FFV) and consequent gas permeabilities.[18, 32] In addition, the disruption of chain packing by pentiptycene units can be confirmed by $d$-spacing values from X-ray diffraction results. WAXD patterns of the pentiptycene-containing polyimide films are shown in Figure 2 and the $d$-spacing values are listed in Table 1 along with FFV data. All WAXD patterns exhibit broad halos instead of sharp peaks, indicating amorphous nature of these glassy polymers. For instance, three broad peaks located at $2 \theta=9.2^{\circ}$ (peak A), $16.3^{\circ}$ (peak B) and $23.2^{\circ}$ (peak C) were observed in the spectra of 6FDA-PPDA( $\left(\mathrm{CF}_{3}\right)$ film, which correspond to $d$-spacing values of 9.6, 5.4 and $3.8 \AA$, respectively. The highest $d$-spacing (peak A) can be identified as the inter-chain distance induced by pentiptycene units because the $d$-spacing value is comparable with the pentiptycene molecular size.[26] When compared with the inter-chain distance of some representative non-pentiptycene-containing polyimide membranes,[16, 33-35] e.g., polyimides derived from 6FDA (Table 1), the $d$-spacing value of peak $\mathrm{A}$ is around $70 \%$ higher. The results verify that rigid, bulky pentiptycene units effectively disrupt chain packing leading to high inter-chain distances. This is further evidenced by the FFV data shown in Table 1, in which pentiptycene-containing polyimides in general show higher fractional free volume than that of conventional non-pentiptycene-containing polyimides. Diffraction peak B can be assigned to the average inter-chain distance of non-pentiptycene segments, and the $d$-spacing values of this peak are comparable with the inter-chain distance of non-pentiptycene-containing polyimides.[16, 33-35] Additionally, $\pi-\pi$ stacking interactions (peak C) were clearly observed in the substituted polyimides of 6FDA-PPDA $\left(\mathrm{CF}_{3}\right)$ and 6FDA-PPDA $\left(\mathrm{CH}_{3}\right)$ due to the presence of many arene rings in the backbone structures, while it was not obvious for 6FDA-PPDA(H). The $\pi-\pi$ stacking could be either inter-chain or intra-chain in nature and these attractive and potentially strong interactions may act as the physical cross-link points and increase the overall chain rigidity, which is believed to be essential for molecular sieving and thus gas selectivity.[36] 


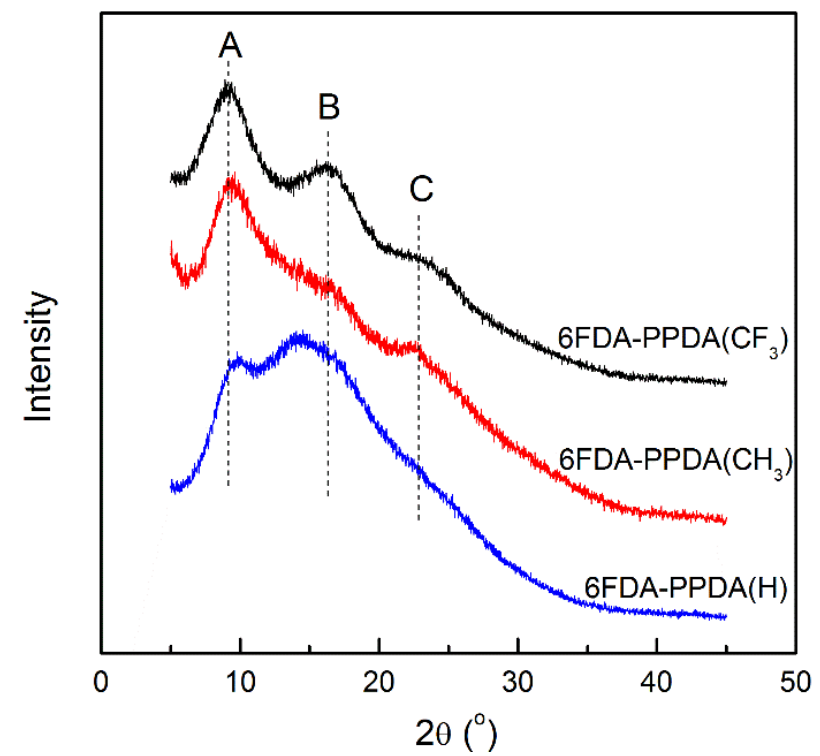

Fig. 2. WAXD patterns of pentiptycene-based polyimide membranes. The vertical dash lines with $d$-spacing values of 9.6, 5.4 and $3.8 \AA$ are indicated for reference.

Since the overall free volume within the membrane is contributed from the inter-chain distances reflected in peak $\mathrm{A}$ and peak $\mathrm{B}$, the overall mean inter-chain distance could be evaluated by qualitatively comparing the relative intensities of these two peaks.[24] As shown in Figure 2, the WAXD patterns of the polyimide membranes are sensitively affected by the variations in the substituent groups of pentiptycene-diamine, i.e., $\mathrm{CF}_{3}, \mathrm{CH}_{3}$ and $\mathrm{H}$ (i.e., non-substituted). For substituted pentiptycene-polyimides (i.e., 6FDA-PPDA $\left(\mathrm{CF}_{3}\right)$ and 6FDA-PPDA $\left.\left(\mathrm{CH}_{3}\right)\right)$, although they show comparable $d$-spacing values for all peaks, the relative intensity of the diffraction peaks varied from each other signifying the effect of substituent groups on inter-chain interactions and chain packing. Compared with 6FDA-PPDA( $\left(\mathrm{CF}_{3}\right)$, 6FDA-PPDA $\left(\mathrm{CH}_{3}\right)$ has a noticeably lower intensity of peak $\mathrm{B}$, suggesting a smaller mean inter-chain distance and thus lower overall fractional free volume (Table 1). This observation is possibly due to the "partial filling" mechanism, whereby the $\mathrm{CH}_{3}$ substituent groups are small enough to easily occupy and (partially) fill the inter-chain voids, leading to the reduction in the mean inter-chain distance and fractional free volume.[13, 26] On the other hand, polymer chain segments in non-substituted 6FDA-PPDA(H) polyimide are likely to pack more efficiently due to the lack of substituent groups of pentiptycene diamine. Thus the contribution of inter-chain distance generated by the pentiptycene units (peak A) is less significant, resulting in a smaller overall mean inter-chain 
distance and lower FFV (18.3\%) than that of $\mathrm{CF}_{3}$-substituted polyimide (19.7\%), as shown in (Table 1). However, the reduction in overall free volume due to the partial filling effect in 6FDA-PPDA $\left(\mathrm{CH}_{3}\right)$ polyimide seems to counteract the contribution of substituted pentiptycene structure, leading to the lowest overall fractional free volume (17.9\%) among three polyimides.

\section{Table 1}

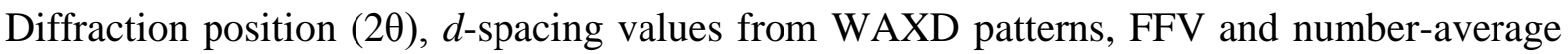
degree of polymerization $\left(X_{n}\right)$ of the 6FDA-pentiptycene polyimides and other 6FDA-based polyimides from literature.

\begin{tabular}{|c|c|c|c|c|c|c|c|c|}
\hline \multirow{2}{*}{ polymer } & \multicolumn{3}{|c|}{$2 \theta\left({ }^{0}\right)$} & \multicolumn{3}{|c|}{$d$-spacing $(\AA)$} & \multirow{2}{*}{ FFV (\%) } & \multirow{2}{*}{$X_{n}$} \\
\hline & A & B & $\mathrm{C}$ & A & B & $\mathrm{C}$ & & \\
\hline 6FDA-PPDA $\left(\mathrm{CF}_{3}\right)$ & 9.2 & 16.3 & 23.2 & 9.6 & 5.4 & 3.8 & $19.7^{a}$ & 39 \\
\hline 6FDA-PPDA $\left(\mathrm{CH}_{3}\right)$ & 9.4 & 16.5 & 23.2 & 9.4 & 5.4 & 3.8 & $17.9^{a}$ & 39 \\
\hline 6FDA-PPDA(H) & 9.9 & 14.4 & - & 8.9 & 6.2 & - & $18.3^{a}$ & 33 \\
\hline 6FDA-BATB[34] & 16.1 & & & 5.5 & & & 15.6 & \\
\hline 6FDA-TMBPS[34] & 16.4 & & & 5.4 & & & 15.9 & \\
\hline 6FDA-mTMPD[35] & 14.3 & & & 6.2 & & & 18.2 & \\
\hline
\end{tabular}

${ }^{a}$ FFV data of 6FDA-PPDA series are from a previous report.[26]

Compared with WAXD, positron annihilation lifetime spectroscopy (PALS) measurements provide more direct and quantitative results of not only the microcavity size but also the microcavity size distribution within the membranes. Generally, non-pentiptycene-containing polyimide membranes display one $o$-Ps component (i.e., lifetime of $\tau_{3}$ ), indicating rather random size distribution of free volume.[5, 37, 38] However, two o-Ps components, i.e., $\tau_{3}$ and $\tau_{4}$, which have annihilation lifetime of $\sim 1.2$ and $\sim 4$ ns, respectively, were observed in the pentiptycene-containing polyimide membranes, suggesting bimodal microcavity size distribution in these membranes. PALS data for the pentiptycene-containing polyimide membranes are listed in Table 2 and the microcavity size distribution profiles are shown in Figure 3. The average microcavity sizes were calculated from the lifetime data based on Equation 1 and two populations of microcavities were identified: ultrafine micropores with an average diameter of $d_{3} \sim 3.5 \AA$ and micropores with an average diameter of $d_{4} \sim 8.0 \AA$. The 
large micropores, which could be ascribed to the pentiptycene units disrupting inter-chain distance (peak A of WAXD pattern), have much larger pore sizes when compared to the kinetic diameters of test gases (i.e., $\mathrm{H}_{2}, \mathrm{CO}_{2}, \mathrm{O}_{2}, \mathrm{~N}_{2}$ and $\mathrm{CH}_{4}$ ), thus enabling fast gas transport in the membranes. On the other hand, the ultrafine microcavities could be assigned to the internal free volume or the partially occupied internal free volume between the benzene "blades” of the pentiptycene units,[13, 26] as well as the relatively tight chain packing (peak B of WAXD pattern). Since the size of the ultrafine microcavities is very comparable to the size of typical gas molecules, they are expected to act as molecular sieving sites facilitating selective transport. The sizes of both microcavity populations in pentiptycene-containing polyimides are smaller than those of the reportedly most permeable polymers, e.g., PTMSP and PMP, which have extremely high gas permeabilities but very low gas selectivities.[39] This is because even the smaller cavities of PTMSP and PMP have average sizes of 5-6 $\AA$ (Table 2), which are much larger than the kinetic diameters of common gas molecules. This comparison suggests that the ultrafine 3-4 $\AA$ micropores in pentiptycene-containing polyimide membranes in this study are expected to be more selective for gas separation while rendering excellent permeability. Additionally, the small cavities may act as the interconnections between the large cavities, constructing low-resistance pathways for fast transport.[5]

Table 2

Microcavity sizes of pentiptycene-containing polyimide membranes by PALS.

\begin{tabular}{|c|c|c|c|c|c|c|}
\hline polymer & $\tau_{3}(\mathrm{~ns})$ & $I_{3}(\%)$ & $\begin{array}{c}\text { cavity } \\
\text { diameter } \\
d_{3}(\AA) \\
\end{array}$ & $\tau_{4}(\mathrm{~ns})$ & $I_{4}(\%)$ & $\begin{array}{c}\text { cavity } \\
\text { diameter } \\
d_{4}(\AA) \\
\end{array}$ \\
\hline 6FDA-PPDA $\left(\mathrm{CF}_{3}\right)$ & $1.18 \pm 0.03$ & $8.2 \pm 0.3$ & $3.87 \pm 0.09$ & $3.71 \pm 0.02$ & $17.9 \pm 0.1$ & $8.15 \pm 0.02$ \\
\hline 6FDA-PPDA $\left(\mathrm{CH}_{3}\right)$ & $1.04 \pm 0.05$ & $10.3 \pm 0.7$ & $3.45 \pm 0.16$ & $3.29 \pm 0.02$ & $17.6 \pm 0.3$ & $7.64 \pm 0.02$ \\
\hline 6FDA-PPDA(H) & $1.13 \pm 0.07$ & $9.0 \pm 0.5$ & $3.74 \pm 0.19$ & $3.32 \pm 0.03$ & $17.8 \pm 0.5$ & $7.69 \pm 0.04$ \\
\hline PTMSP[39] & 1.7 & 7.4 & 5.1 & 8.8 & 34 & 12.4 \\
\hline PMP[39] & 2.3 & 8.4 & 6.2 & 7.6 & 29.4 & 11.6 \\
\hline
\end{tabular}

Microcavity size distribution plays an equally, if not more, important role as the actual cavity size in dictating the gas transport properties of the membranes, which could be finely 
tailored by the substituent groups as well. As shown in Figure 3, all pentiptycene polyimide membranes display bimodal size distribution of free volume featuring large microcavities of $\sim 8.0 \AA$ and small microcavities of $~ 3.5 \AA$. In particular, substitution with bulky $\mathrm{CF}_{3}$ groups shifts the size of both categories of microcavities to higher values when compared to non-substituted counterpart, e.g., the average diameter of larger microcavities increased from $7.69 \AA$ for 6FDA-PPDA(H) to $8.15 \AA$ for 6 FDA-PPDA $\left(\mathrm{CF}_{3}\right)$. However, substitution of $\mathrm{CH}_{3}$ groups did not lead to noticeable increase in the size of larger microcavities, presumably due to our previously proposed "partial filling" mechanism, in which the $\mathrm{CH}_{3}$ groups may reside in and occupy the internal microcavities of pentiptycene units, counteracting the effect of bulky substitution in disrupting chain packing.[15, 27]. The effect of substituent groups seems to be more pronounced in regulating the size of the smaller microcavities. As can be seen, 6FDA-PPDA $\left(\mathrm{CH}_{3}\right)$ has a big reduction in the size of the smaller microcavities due to the same effect of $\mathrm{CH}_{3}$ partial filling. Comparisons of the full width at half maximum (FWHM) of the distribution peaks further corroborate the "partial filling” mechanism. As shown, 6FDA-PPDA $\left(\mathrm{CF}_{3}\right)$ and 6FDA-PPDA(H) have comparatively narrower cavity size distributions in both categories of peaks with respect to 6FDA-PPDA $\left(\mathrm{CH}_{3}\right)$. In particular, the FWHM of both peaks of 6FDA-PPDA $\left(\mathrm{CH}_{3}\right)$ is around twice those of 6FDA-PPDA $\left(\mathrm{CF}_{3}\right)$ and 6FDA-PPDA(H). Based on the "partial filling" mechanism, the relatively small $\mathrm{CH}_{3}$ substituent groups likely occupy the internal microcavities of pentiptycene units; therefore, some of the microcavities are filled by $\mathrm{CH}_{3}$ substituent groups and some of them are not, leading to the broadening of cavity size distribution and an overall reduction of the average cavity size in 6 FDA-PPDA $\left(\mathrm{CH}_{3}\right)$. In the case of $6 \mathrm{FDA}-\mathrm{PPDA}\left(\mathrm{CF}_{3}\right), \mathrm{CF}_{3}$ groups are less likely to occupy the internal microcavities due to their bulkiness and act mainly as "spacers" to increase inter-chain spacing as well as overall microcavity size. Therefore, no noticeable peak broadening occurs in 6FDA-PPDA $\left(\mathrm{CF}_{3}\right)$ as compared to non-substituted 6FDA-PPDA(H). The PALS analysis results regarding free volume size and size distribution are consistent with WAXD data and FFV results (Table 1), in which the $\mathrm{CF}_{3}$-substituted polyimide has the highest average inter-chain distance and FFV while the $\mathrm{CH}_{3}$-substituted one has the smallest values due to microcavity filling effect. 


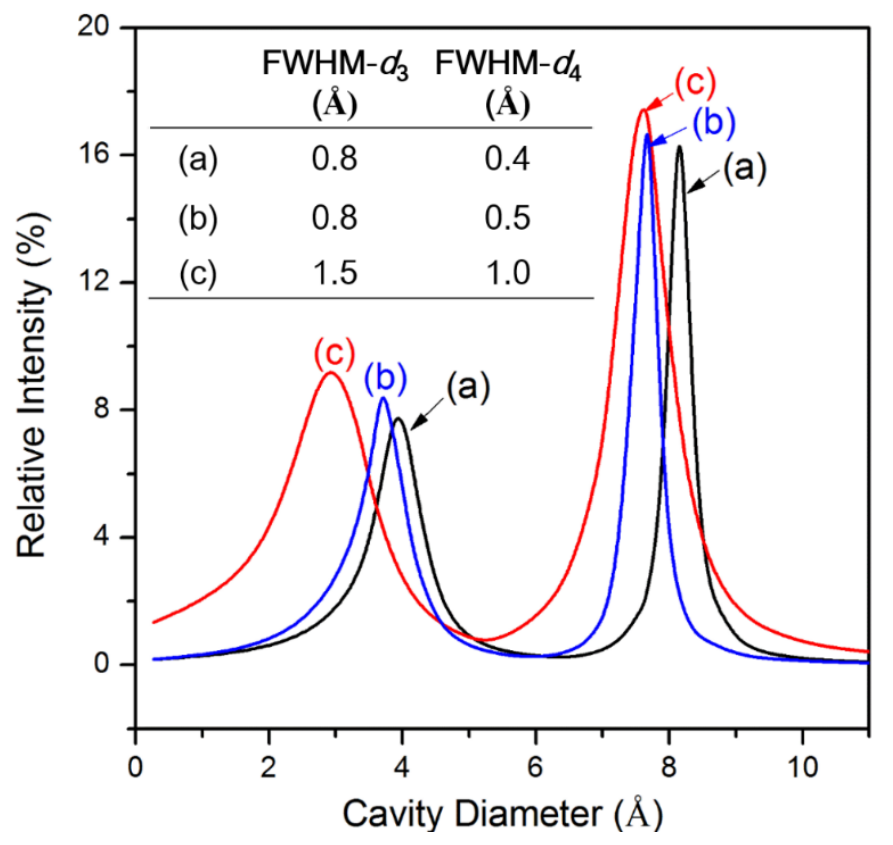

Fig. 3. Comparison of cavity size and size distribution of (a) 6FDA-PPDA( $\left(\mathrm{CF}_{3}\right)$, (b) 6FDA-PPDA(H) and (c) 6FDA-PPDA $\left(\mathrm{CH}_{3}\right)$ obtained from positron annihilation lifetime spectroscopy (PALS). The inlet table lists the FWHM values for both peaks.

\subsection{Geometric modeling on chain conformation and intra-chain rigidity}

In glassy polymers like the ones in this study, free volume generally originates from: 1) inefficiencies in polymer chain/segment packing in the solid state, and 2) local molecular motion of polymer segments, which effectively opens transient gaps in the polymer matrix and allows penetrant molecules to diffuse through the polymer. In this regard, gas permeation properties of the polyimide membranes are strongly influenced by the conformational characteristics of their constituent backbone as well as chain rigidity because both determine the local chain dynamics. Polymer conformational structure and the first approximation of the differences in intra-chain rigidity were explored by molecular modeling. Generally, tortuous backbones, which is a typical feature of microporous polymer materials, were observed from the energy-minimized conformational structures (Figure 1b), which is ascribed to the bulky and shape persistent pentiptycene units inhibiting free rotation of the single bonds. The effect of substitution on the torsional freedom of imide bond is presented in Figure 4 in the form of rotational energy, in which the energy barrier profile was obtained by rotating one repeat unit of the polyimides around the imide bond (highlighted in Figure $1 \mathrm{a}$ ) from $0^{\circ}$ to $360^{\circ}$. As 
shown, 6FDA-PPDA $\left(\mathrm{CF}_{3}\right)$ exhibited a higher rotational energy barrier $\left(14.3 \mathrm{kcal} \cdot \mathrm{mol}^{-1}\right)$ compared with the non-substituted polyimide 6FDA-PPDA(H) $\left(12.8 \mathrm{kcal} \cdot \mathrm{mol}^{-1}\right)$, indicating higher intra-chain rigidity of 6FDA-PPDA $\left(\mathrm{CF}_{3}\right)$ due to the steric hindrance of the bulky $\mathrm{CF}_{3}$ substituent groups. On the other hand, 6FDA-PPDA $\left(\mathrm{CH}_{3}\right)$ shows a slightly lower energy barrier $\left(12.6 \mathrm{kcal} \cdot \mathrm{mol}^{-1}\right)$ than that of 6FDA-PPDA(H), possibly due to the plasticizing effect of the smaller $\mathrm{CH}_{3}$ groups, in which the small alkyl pendant groups may act as a build-in solvent or lubricant and decrease the rotational energy of imide bond.[40] The relatively low rotational energy barrier of imide bonds for 6FDA-PPDA $\left(\mathrm{CH}_{3}\right)$ also facilitates the relaxation of 6FDA-PPDA $\left(\mathrm{CH}_{3}\right)$ chains into more compact chain packing state, resulting in the lowest FFV across the series. The increased rigidity of $\mathrm{CF}_{3}$-substituted imide bonds supports the increased inter-chain $d$-spacing values, microcavity size, FFV and gas permeabilities,[26] which correspond to the improved development of microporosity, relative to 6FDA-PPDA(H) and 6FDA-PPDA $\left(\mathrm{CH}_{3}\right)$. The above results confirm the important role of chain rigidity that disrupts chain packing in the development of microporosity.[41, 42]

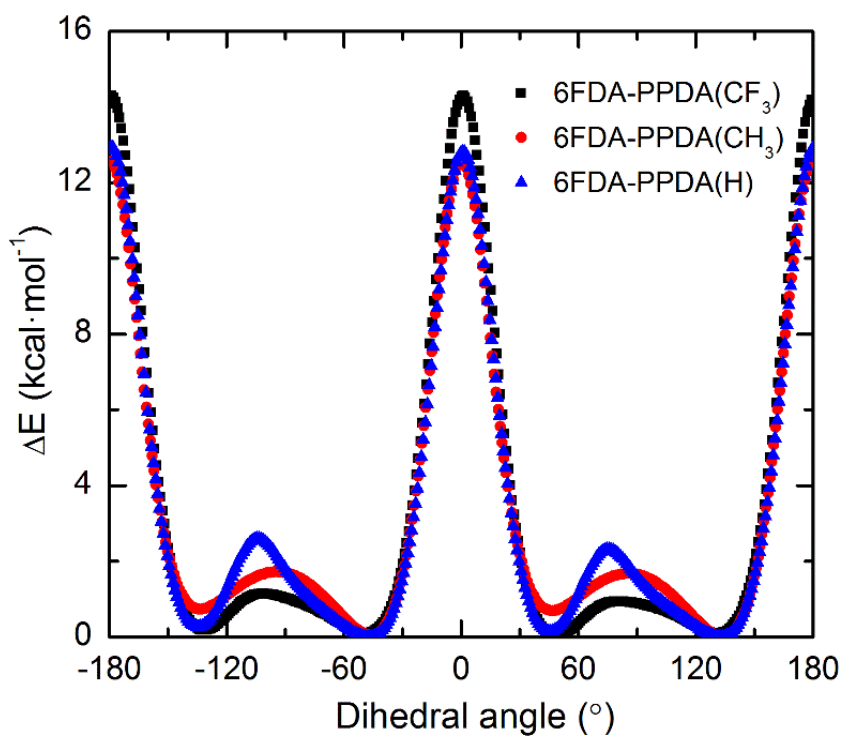

Fig. 4. Rotational energy of a repeating unit for the imide bond of pentiptycene-based polyimides.

\subsection{Fundamental gas transport properties}

Gas transport through dense polymeric membranes are usually described by the solution-diffusion model, in which the penetrant gases firstly dissolve into the high pressure surface of the membranes, diffuse through the film along the concentration gradient, and then 
desorbs from the low pressure surface.[43] Based on the model, gas permeability can be written as a product of solubility coefficient and diffusivity coefficient: $P=D \times S$. Since diffusivity coefficient $(D)$ is closely related to the penetrant size and the free volume in the membrane, and solubility coefficient $(S)$ is dependent on the condensability of the penetrant gases and the polymer-penetrant interactions, the analysis of respective contribution from thermodynamic solubility aspect and kinetic diffusivity aspect may provide profound understanding of micro-cavity architecture in the membranes as well as the interactions between penetrant gases and polymer membranes. Diffusivity coefficients were calculated using the time-lag method and solubility coefficients were determined based on solution-diffusion model. The results are listed in Table 3 as well as schematically shown in Figure 5 and Figure S1 in the supporting information to highlight the effect of substituent groups on diffusivity and solubility. For all three pentiptycene-containing polyimide membranes, the diffusivity coefficients generally reflects the order of kinetic diameter of penetrant gases, indicating a dominant role of diffusivity in gas transport (Figure S1). The deviation of $\mathrm{CO}_{2}$ diffusivity coefficient with kinetic diameter is possibly due to the interactions between the polar $\mathrm{CO}_{2}$ molecules and the pentiptycene-containing polyimides. As shown in Figure 5a, by dropping $\mathrm{CO}_{2}$ data, the diffusivity coefficients of all other four gases correlate well with the squared kinetic diameter, confirming the dominant contribution of diffusivity towards gas transport in these pentiptycene-containing polyimides. A linear relationship between the logarithm of gas solubility as a function of penetrant critical temperature was observed in Figure 5b, revealing that the gas sorption in these 6FDA-PPDA membranes is mainly determined by the condensability of the test gases.[44] Additionally, all gases show very similar solubility coefficients regardless of polymer structure, which further confirms that gas transport is dominated by diffusivity in these pentiptycene-containing polyimides. Although $\mathrm{CO}_{2}$ has an abnormally lower diffusivity coefficient compared to $\mathrm{O}_{2}$, $\mathrm{CO}_{2}$ exhibits the highest solubility coefficient among the test gases. For example, $\mathrm{O}_{2}$ diffusivity is about two times of $\mathrm{CO}_{2}$ diffusivity in $6 \mathrm{FDA}-\mathrm{PPDA}\left(\mathrm{CF}_{3}\right)$ film, while $\mathrm{CO}_{2}$ solubility is 6.5 times higher than that of $\mathrm{O}_{2}$ (Table 3), resulting in a faster permeation of $\mathrm{CO}_{2}$ over $\mathrm{O}_{2}$ in the membranes. A similar trend was observed in KAUST-PI polymers[10, 11, 23] and Tröger's base-PI polymers.[24] 
Table 3

Pure gas permeabilities $(P)$, diffusivity coefficients $(D)$, solubility coefficients $(S)$ and ideal selectivities $(\alpha)$ for pentiptycene-based polyimides $\left(10 \mathrm{~atm}, 35{ }^{\circ} \mathrm{C}\right)$

\begin{tabular}{|c|c|c|c|c|c|c|c|c|c|}
\hline \multirow[b]{2}{*}{ Polymer } & \multirow[b]{2}{*}{$\mathrm{H}_{2}$} & \multirow[b]{2}{*}{$\mathrm{CO}_{2}$} & \multirow[b]{2}{*}{$\mathrm{O}_{2}$} & \multirow[b]{2}{*}{$\mathrm{N}_{2}$} & \multirow[b]{2}{*}{$\mathrm{CH}_{4}$} & \multicolumn{4}{|c|}{ Ideal Selectivity $(\alpha)$} \\
\hline & & & & & & $\begin{array}{c}\mathrm{H}_{2} / \\
\mathrm{N}_{2} \\
\end{array}$ & $\begin{array}{l}\mathrm{H}_{2} / \\
\mathrm{CH}_{4} \\
\end{array}$ & $\begin{array}{l}\mathrm{O}_{2} / \\
\mathrm{N}_{2} \\
\end{array}$ & $\begin{array}{l}\mathrm{CO}_{2} / \\
\mathrm{CH}_{4} \\
\end{array}$ \\
\hline \multicolumn{10}{|l|}{ 6FDA-PPDA(H) } \\
\hline${ }^{a} P[26]$ & $131 \pm 2$ & $73 \pm 3$ & $17 \pm 1$ & $3.2 \pm 0.1$ & $2.5 \pm 0.1$ & 41 & 52 & 5.3 & 29 \\
\hline$D$ & $2260 \pm 63$ & $49 \pm 2$ & $91 \pm 3$ & $26 \pm 1$ & $5.6 \pm 0.2$ & 87 & 404 & 3.5 & 8.7 \\
\hline$S$ & $0.44 \pm 0.02$ & $11 \pm 1$ & $1.4 \pm 0.2$ & $0.93 \pm 0.06$ & $3.4 \pm 0.3$ & 0.47 & 0.13 & 1.5 & 3.4 \\
\hline \multicolumn{10}{|l|}{ 6FDA-PPDA $\left(\mathrm{CH}_{3}\right)$} \\
\hline$P[26]$ & $100 \pm 1$ & $55 \pm 3$ & $12 \pm 1$ & $2.4 \pm 0.1$ & $2.0 \pm 0.1$ & 42 & 50 & 5.0 & 28 \\
\hline$D$ & $2328 \pm 64$ & $39 \pm 2$ & $62 \pm 2$ & $18 \pm 1$ & $4.8 \pm 0.2$ & 132 & 482 & 3.5 & 8.1 \\
\hline$S$ & $0.33 \pm 0.02$ & $11 \pm 1$ & $1.5 \pm 0.2$ & $1.0 \pm 0.1$ & $3.2 \pm 0.3$ & 0.32 & 0.10 & 1.4 & 3.4 \\
\hline \multicolumn{10}{|l|}{ 6FDA-PPDA $\left(\mathrm{CF}_{3}\right)$} \\
\hline$P[26]$ & $188 \pm 2$ & $132 \pm 6$ & $30 \pm 1$ & $7.0 \pm 0.1$ & $5.5 \pm 0.3$ & 27 & 34 & 4.3 & 24 \\
\hline$D$ & $2993 \pm 183$ & $93 \pm 6$ & $143 \pm 9$ & $55 \pm 4$ & $14 \pm 1$ & 54 & 216 & 2.6 & 6.7 \\
\hline$S$ & $0.48 \pm 0.03$ & $11 \pm 2$ & $1.6 \pm 0.2$ & $0.96 \pm 0.08$ & $3.0 \pm 0.4$ & 0.50 & 0.16 & 1.7 & 3.6 \\
\hline${ }^{b} \mathrm{PPO}[43] P$ & 61 & 61 & 16.8 & 4.1 & 4.3 & 15 & 14 & 4.1 & 14 \\
\hline${ }^{c} \mathrm{CA}-2.45[45] P$ & 12 & 4.8 & 0.82 & 0.15 & 0.15 & 80 & 80 & 5.5 & 32 \\
\hline $\operatorname{Matrimid}^{\circledR}[1] P$ & 18 & 10 & 2.1 & 0.32 & 0.28 & 56 & 64 & 6.6 & 36 \\
\hline 6FDA-DAM[46] $P$ & 516 & 431 & 109 & 32 & 26 & 16 & 20 & 3.5 & 17 \\
\hline 6FDA-durene[46] $P$ & 549 & 440 & 122 & 36 & 28 & 15 & 19 & 3.4 & 16 \\
\hline PIM-1[47] $P$ & 3600 & 6500 & 1300 & 340 & 430 & 11 & 8.4 & 3.8 & 15 \\
\hline PIM-7[48] $P$ & 860 & 1100 & 190 & 42 & 62 & 20 & 14 & 4.5 & 18 \\
\hline PIM-PI-1[21] $P$ & 530 & 1100 & 150 & 47 & 77 & 11 & 6.9 & 3.2 & 14 \\
\hline PIM-PI-8[21] $P$ & 1600 & 3700 & 545 & 160 & 260 & 10 & 6.2 & 3.4 & 14 \\
\hline
\end{tabular}

${ }^{a}$ Units: $P$, Barrer, $10^{-10} \mathrm{~cm}^{3}(\mathrm{STP}) / \mathrm{cm} \cdot \mathrm{s} \cdot \mathrm{cmHg} ; D, 10^{-9} \mathrm{~cm}^{2} / \mathrm{s} ; S, \mathrm{~cm}^{3}(\mathrm{STP}) / \mathrm{cm}^{3} \cdot$ atm, measured at $10 \mathrm{~atm}, 35{ }^{\circ} \mathrm{C}$. ${ }^{b} \mathrm{Poly}\left(2,6\right.$-dimethylphenylene oxide). ${ }^{c}$ Cellulose acetate (2.45 degree of acetylation).

The effects of substituent groups on the microcavity architecture and gas transport properties are clearly revealed by gas diffusivity analysis since the solubility coefficients 
show negligible difference for different polymers (Figure 5b). As shown in Table 3, the incorporation of bulky $\mathrm{CF}_{3}$ substituent groups induces significant increase in diffusivity coefficients for all gases, e.g., 6FDA-PPDA $\left(\mathrm{CF}_{3}\right)$ exhibits a $\mathrm{CO}_{2}$ diffusion coefficient that is almost two times of that of 6FDA-PPDA(H). Conversely, the introduction of smaller $\mathrm{CH}_{3}$ substituent groups leads to lower diffusivity coefficients and consequent lower gas permeabilities than those of the non-substituted 6FDA-PPDA(H) polyimide. The observed trends in $D$ and $S$ changes as a function of substituent groups is consistent with the trend in gas permeability and confirm our previously proposed "partial filling” mechanism,[13, 26] in which the relatively small $\mathrm{CH}_{3}$ groups can (partially) occupy the internal free volume in the membranes, resulting in decreased overall FFV and gas permeability.
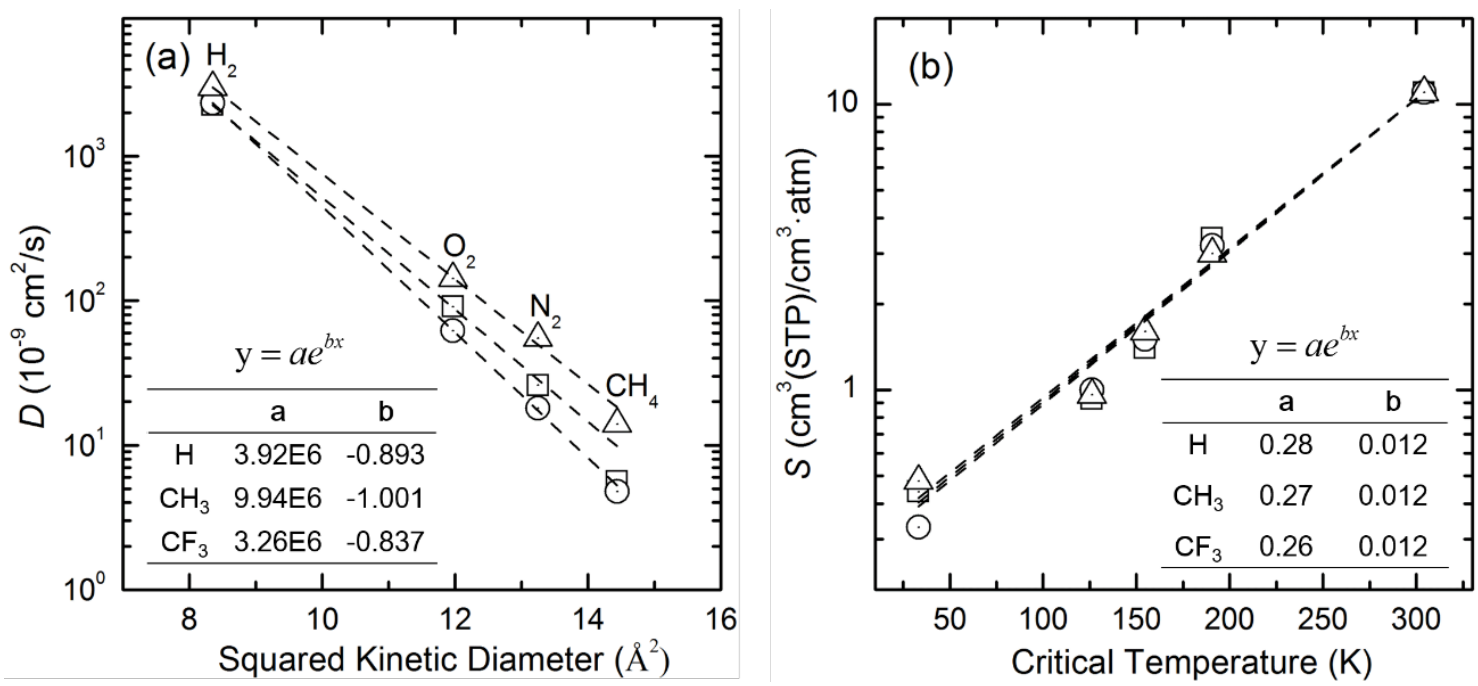

Fig. 5. (a) Diffusivity coefficients $(D)$ as a function of the squared kinetic diameter of penetrant gases (note: $\mathrm{CO}_{2}$ data is neglected in this plot due to its polar nature) and (b) solubility coefficients $(S)$ as a function of the critical temperature of penetrant gases for 6FDA-PPDA $\left(\mathrm{CF}_{3}\right)(\triangle)$, 6FDA-PPDA(H) $(\square)$, and 6FDA-PPDA $\left(\mathrm{CH}_{3}\right)(\bigcirc)$. The dash lines denote exponential fittings of the diffusivity or solubility coefficients, and the substituent groups were used to represent the corresponding polymers. All data are based on gas permeation measurements at $10 \mathrm{~atm}$ and $35^{\circ} \mathrm{C}$.

Accordingly, the ideal selectivity ( $\alpha_{A B}$ ) of two different gases is contributed from both solubility selectivity $\left(S_{A} / S_{B}\right)$ and diffusivity selectivity $\left(D_{A} / D_{B}\right)$. As shown in Table 3, solubility selectivity and diffusivity coefficient contribute almost equally to the separation of the $\mathrm{O}_{2} / \mathrm{N}_{2}$ gas pair; while for $\mathrm{CO}_{2} / \mathrm{CH}_{4}$ gas pair, diffusivity selectivity plays a more significant role than solubility selectivity. Solubility selectivities for different substituted 
polymers are very similar, while incorporation of bulky $\mathrm{CF}_{3}$ reduced the diffusivity selectivities slightly. It is notable that the pentiptycene-containing polyimide membranes hold great promise for $\mathrm{H}_{2}$ related gas separations, e.g., gas selectivities for $\mathrm{H}_{2} / \mathrm{N}_{2}$ and $\mathrm{H}_{2} / \mathrm{CH}_{4}$ gas pairs are as high as the most selective commercial polymers like Matrimid ${ }^{\circledR}$ and cellulose acetate, but with much higher permeability.[1, 45] The highly selective hydrogen transport in these membranes can be ascribed to the presence of ultrafine micropores with a small cavity size of $d_{3} \sim 3.5 \AA$, which most likely originates from the internal free volume or the partially occupied internal free volume of pentiptycene units, as discussed previously.

\subsection{Physical aging behavior}

It has been found that high permeability polymers typically suffer a degradation in transport properties over time due to the phenomenon of physical aging, in which polymer segments relax and compact toward a more tightly packed thermodynamic equilibrium state, resulting in significant decrease of gas permeability, inter-chain distance, and fractional free volume, etc.[1] As this can affect their viability of industrial applications, the physical aging resistance of the pentiptycene-based polyimide membranes was evaluated. Pure gas permeabilities of pentiptycene-containing polyimide membranes, which were aged for 130 days for 6FDA-PPDA $\left(\mathrm{CF}_{3}\right)$ and 240 days for 6FDA-PPDA $\left(\mathrm{CH}_{3}\right)$ and 6FDA-PPDA(H) under ambient atmospheric conditions, were tested using the same testing conditions (3-17 atm feed pressure and $35{ }^{\circ} \mathrm{C}$ ) as those applied to the fresh films.[26] The plots of pure gas permeability as a function of feed pressure for aged samples are shown in Figure S2. The pure gas permeabilities of aged samples displayed the same independence on the feed pressure as that was observed in fresh films. Comparisons of pure gas permeabilities and ideal selectivities at 10 atm between aged and fresh films are illustrated in Figure 6. In general, no obvious physical aging was observed for all three pentiptycene-containing polyimide films after they were aged for more than 130 days, i.e., pure gas permeabilities of $\mathrm{CO}_{2}, \mathrm{~N}_{2}$ and $\mathrm{CH}_{4}$ of aged samples are equal to or slightly lower than those of the fresh ones. The slight increase of $\mathrm{H}_{2}$ permeabilities in aged 6FDA-PPDA $\left(\mathrm{CF}_{3}\right)$ and 6FDA-PPDA $\left(\mathrm{CH}_{3}\right)$ films might originate from local relaxation and rearrangement of chain segments, whereby very small microcavities (likely $\sim 3 \AA$ ) are likely generated facilitating $\mathrm{H}_{2}$ transport. Accordingly, the ideal selectivities of aged samples remain almost unchanged from fresh samples. 

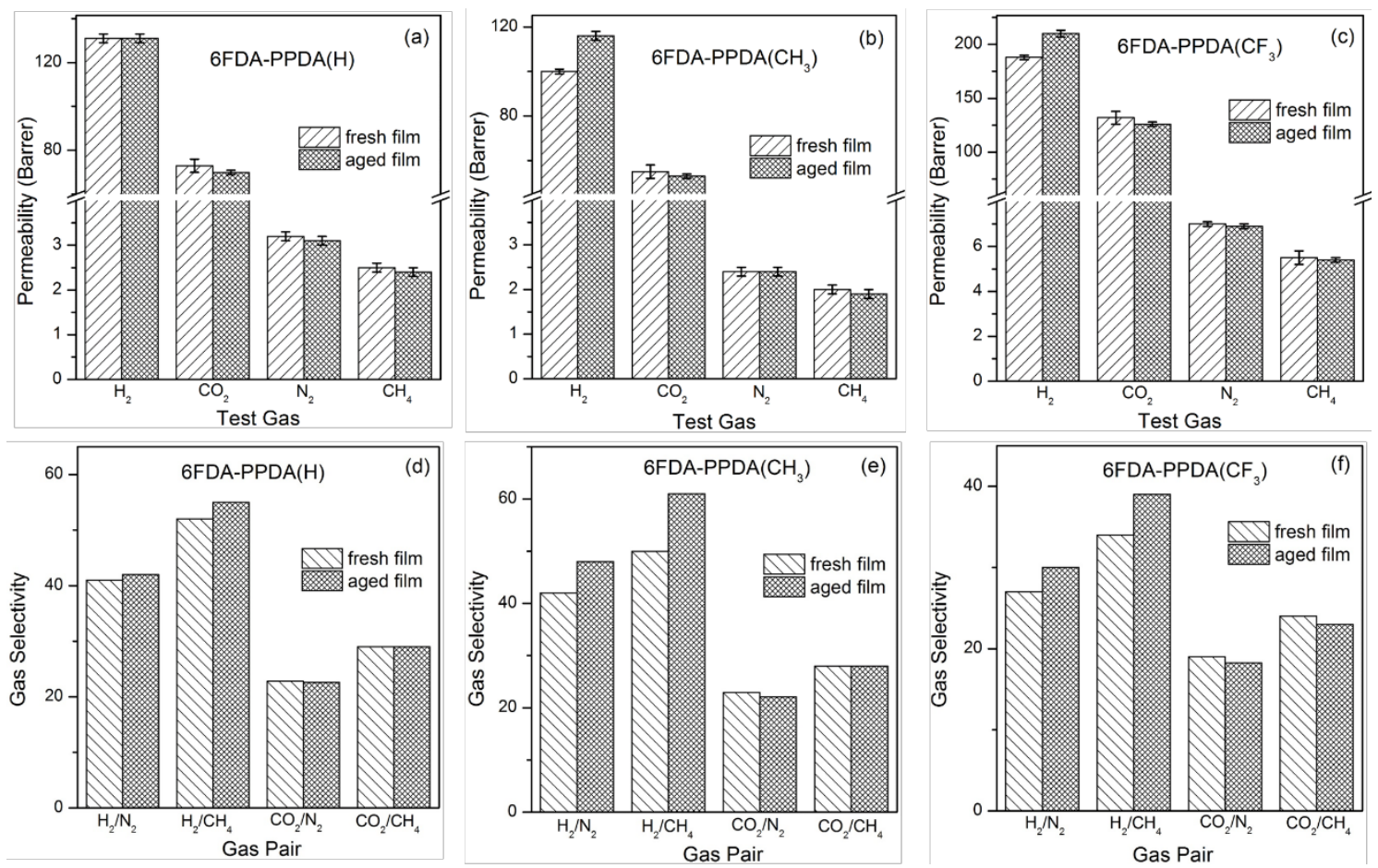

Fig. 6. Comparisons of pure gas permeabilities (a-c) and ideal selectivities (d-f) between fresh and aged 6FDA-PPDA polyimide membranes.

The excellent resistance against physical aging of pentiptycene-containing polyimides in this study may be ascribed to the relatively "stable" free volume architecture in these membranes. As described before, the main driving force for physical aging is the departure of polymer's specific volume from its equilibrium value.[1, 49] However, a marked fraction of the free volume in pentiptycene-containing polyimide membranes comes from the internal free volume defined by the molecular configuration of pentiptycene structure. Different from conventional free volume induced by conformational characteristics in non-pentiptycene-containing polymers, these configuration-induced free volumes are intrinsic in nature, which are less likely susceptible to compaction due to polymer segments relaxation. Additionally, the relatively flexible ether bonds in the polymer backbones might contribute to polymer segment relaxation and packing during the film formation, and result in a relatively close-to-equilibrated state in the fresh films. As a result, the driving force (the difference between specific volume and equilibrium volume) for physical aging is much less in these pentiptycene-polyimides as compared with other microporous polymers like PIMs. The weak physical aging effect was also verified by WAXD spectra analysis, in which aged films 
exhibit almost the same diffraction patterns and $d$-spacing values for 6FDA-PPDA( $\left(\mathrm{CF}_{3}\right)$ and 6FDA-PPDA $\left(\mathrm{CH}_{3}\right)$ as those of corresponding fresh films, as shown in Figure S3 and tabulated in Table S1. Only minor changes were observed for the aged 6FDA-PPDA(H) film with an increase of $5.6 \%$ in $d$-spacing value for peak $\mathrm{A}$ and a decrease of $3.2 \%$ for peak $\mathrm{B}$. Additionally, as shown in Table S1, the aged films showed almost the same FFV values as those of fresh films. Both WAXD and FFV measurements suggest that aging process affected only at local sites, which most likely changed the connectivity of microcavities and/or induced local redistribution of free volume elements. Diffusivity and solubility coefficients were also calculated for aged 6FDA-PPDA films (Table S2), which show very comparable $D$ and $S$ values compared to fresh films, further signifying stable micro-cavity architecture in these membranes wherein only local chain relaxation occurs and there are no coordinated large scale chain rearrangement events.

The permeability-selectivity tradeoff for $\mathrm{H}_{2} / \mathrm{N}_{2}$ and $\mathrm{H}_{2} / \mathrm{CH}_{4}$ gas pairs of both fresh and aged pentiptycene-containing polyimides are plotted in Figure 7 to evaluate their $\mathrm{H}_{2}$-related gas separation performance by comparing with some commercial polymers and previously reported 6FDA-based polyimides.[6, 7] Compared with commercial gas separation materials, e.g., Matrimid ${ }^{\circledR}$ polyimide, poly(2,6-dimethylphenylene oxide) (PPO) and cellulose acetate (CA-2.45), pentiptycene-containing polyimides exhibit dramatic improvements in $\mathrm{H}_{2} / \mathrm{N}_{2}$ and $\mathrm{H}_{2} / \mathrm{CH}_{4}$ permeability-selectivity tradeoff, due to bimodal size distribution of free volume featured in these membranes whereby large-size microcavities allow high permeability and small-size ones enable precise size sieving. In addition, aged 6FDA-PPDA membranes outperform slightly fresh polyimides with both higher $\mathrm{H}_{2}$ permeability and better $\mathrm{H}_{2}$-related selectivities, revealing that local chain relaxation during physical aging induces enhancement of size sieving properties for hydrogen-related gas pairs. When compared to previously reported 6FDA-based polyimides (e.g., 6FDA-DAM and 6FDA-durene),[46] pentiptycene-based polyimides exhibit relatively lower gas permeabilities (also shown in Table 3) although they have comparable FFV. This is possibly due to the relatively flexible ether linkages on the backbones of these pentiptycene-polyimides, whose local rotational motions might block some of the connectivity between microcavities. However, pentiptycene-based polyimides exhibit much higher hydrogen-related gas selectivities, which 
can be beneficial when high purity product is desired.
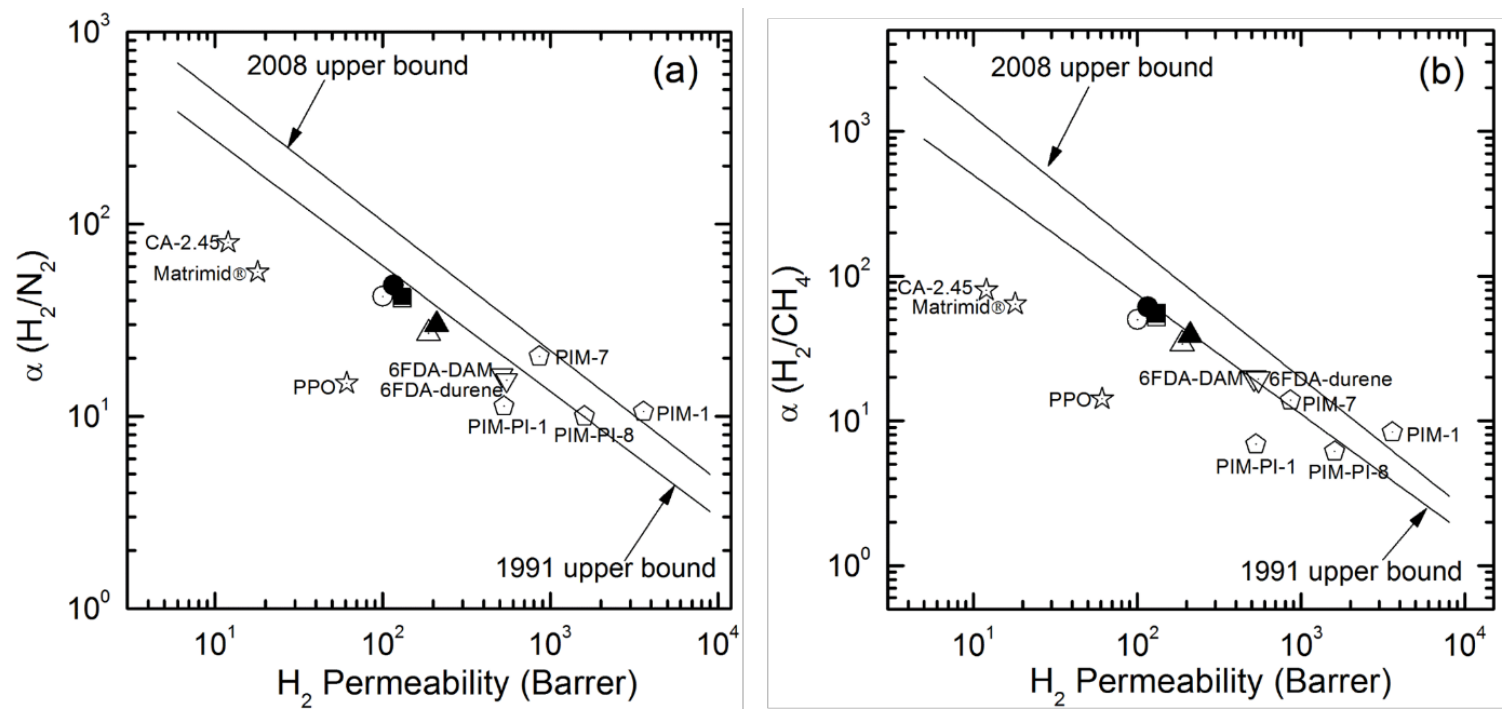

Fig. 7. Permeability-selectivity upper bound plots of fresh (open) and aged (solid) 6FDA-PPDA $\left(\mathrm{CF}_{3}\right)\left(\triangle\right.$ - fresh; $\boldsymbol{\Delta}$ - aged), 6FDA-PPDA $\left(\mathrm{CH}_{3}\right)(\mathrm{O}$ - fresh; - - aged) and 6FDA-PPDA(H) ( $\square$ - fresh; - aged) films for (a) $\mathrm{H}_{2} / \mathrm{N}_{2}$ and (b) $\mathrm{H}_{2} / \mathrm{CH}_{4}$ gas pairs. Data points of commercial polymers: Matrimid ${ }^{\circledR}$ [1] PPO[43] CA-2.45[45] 6FDA-DAM[46] 6FDA-durene[46] PIM-1[47] PIM-7[48] PIM-PI-1[21] and PIM-PI-8[21] are included for comparison.

\section{Conclusions}

The research reported herein provides a critical understanding of the fundamental relationship between polymer structures and gas transport properties in the newly reported pentiptycene-containing polyimide membranes. The incorporation of rigid H-shaped pentiptycene units into the polyimide backbone efficiently disrupts chain packing as evidenced by WAXD, resulting in large inter-chain spacing and consequently large fractional free volume. PALS analysis confirmed microporous nature of this series of polyimide membranes and revealed bimodal size distribution of free volume in these polymers, which is responsible for their excellent $\mathrm{H}_{2}$-related separation performance. The size and bimodal size distribution are sensitively affected by substitution on pentiptycene units. The incorporation of bulky $\mathrm{CF}_{3}$ substituent groups led to increased cavity size with no change in size distribution when compared to non-substituted one; while $\mathrm{CH}_{3}$-substituted 6FDA-PPDA( $\left(\mathrm{CH}_{3}\right)$ showed reduced cavity sizes and a much broadened size distribution due to the "partial filling" effect. Simulation results demonstrated that pentiptycene-containing polyimides propagate through space in tortuous chain conformations, and the increased rotation energy of the imide 
bond due to introduction of $\mathrm{CF}_{3}$ groups resulted in a more rigid and contorted backbone structure than the other two polymers. Owing to the pentiptycene-induced microporosity, pure gas permeabilities of the membranes were significantly higher compared to commercial gas separation polymers, and size sieving contribution (i.e., diffusivity) played a dominant role, making them very promising for $\mathrm{H}_{2}$-related gas purification. These pentiptycene-containing polyimide membranes showed excellent physical aging resistance due to "stable" configuration-induced free volume architecture created by shape-persistent pentiptycene units. The local chain relaxation during physical aging refined free volume architecture leading to improved $\mathrm{H}_{2}$-related separation performance in aged films.

\section{AUTHOR INFORMATION}

\section{Corresponding Author}

*Telephone: +1-574-631-3453 Fax: +1-574-631-8366 E-mail: rguo@nd.edu

\section{ACKNOWLEDGEMENTS}

R. Guo gratefully acknowledges the financial support of the Division of Chemical Sciences, Biosciences, and Geosciences, Office of Basic Energy Sciences of the U.S. Department of Energy (DOE) under Award DE-SC0010330. S. Luo acknowledges the partial financial support from the Center of Sustainable Energy at Notre Dame via the ND Energy Postdoctoral Fellowship Program. C.M. Doherty is supported by the Australian Research Council (DE40101359). The authors would like to thank the Materials Characterization Facility (MCF) of ND Energy center and the Center for Environmental Science and Technology (CEST) at Notre Dame; portions of this research were performed with instruments at these facilities.

\section{REFERENCES}

[1] D.F. Sanders, Z.P. Smith, R. Guo, L.M. Robeson, J.E. McGrath, D.R. Paul, B.D. Freeman, Energy-efficient polymeric gas separation membranes for a sustainable future: A review, Polymer, 54 (2013) 4729-4761.

[2] R.W. Baker, B.T. Low, Gas separation membrane materials: A perspective, Macromolecules, 47 (2014) 6999-7013. 
[3] Y. Yampolskii, Polymeric gas separation membranes, Macromolecules, 45 (2012) 3298-3311.

[4] H.Q. Lin, E. Van Wagner, B.D. Freeman, L.G. Toy, R.P. Gupta, Plasticization-enhanced hydrogen purification using polymeric membranes, Science, 311 (2006) 639-642.

[5] H.B. Park, C.H. Jung, Y.M. Lee, A.J. Hill, S.J. Pas, S.T. Mudie, E. Van Wagner, B.D. Freeman, D.J. Cookson, Polymers with cavities tuned for fast selective transport of small molecules and ions, Science, 318 (2007) 254-258.

[6] L.M. Robeson, Correlation of separation factor versus permeability for polymeric membranes, J. Membr. Sci., 62 (1991) 165-185.

[7] L.M. Robeson, The upper bound revisited, J. Membr. Sci., 320 (2008) 390-400.

[8] C.G. Bezzu, M. Carta, A. Tonkins, J.C. Jansen, P. Bernardo, F. Bazzarelli, N.B. McKeown, A spirobifluorene-based polymer of intrinsic microporosity with improved performance for gas separation, Adv. Mater., 24 (2012) 5930-5933.

[9] M. Carta, M. Croad, R. Malpass-Evans, J.C. Jansen, P. Bernardo, G. Clarizia, K. Friess, M. Lanc, N.B. McKeown, Triptycene induced enhancement of membrane gas selectivity for microporous Troger's base polymers, Adv. Mater., 26 (2014) 3526-3531.

[10] B.S. Ghanem, R. Swaidan, E. Litwiller, I. Pinnau, Ultra-microporous triptycene-based polyimide membranes for high-performance gas separation, Adv. Mater., 26 (2014) 3688-3692.

[11] B.S. Ghanem, R. Swaidan, X. Ma, E. Litwiller, I. Pinnau, Energy-efficient hydrogen separation by AB-type ladder-polymer molecular sieves, Adv. Mater., 26 (2014) 6696-6700.

[12] Y. Xiao, B.T. Low, S.S. Hosseini, T.S. Chung, D.R. Paul, The strategies of molecular architecture and modification of polyimide-based membranes for $\mathrm{CO}_{2}$ removal from natural gas: A review, Prog. Polym. Sci., 34 (2009) 561-580.

[13] J.R. Wiegand, Z.P. Smith, Q. Liu, C.T. Patterson, B.D. Freeman, R. Guo, Synthesis and characterization of triptycene-based polyimides with tunable high fractional free volume for gas separation membranes, J. Mater. Chem. A, 2 (2014) 13309-13320.

[14] S. Luo, K.A. Stevens, J.S. Park, J.D. Moon, Q. Liu, B.D. Freeman, R. Guo, Highly $\mathrm{CO}_{2}$-selective gas separation membranes based on segmented copolymers of poly(ethylene oxide) reinforced with pentiptycene-containing polyimide hard segments., ACS Appl. Mater. 
Interfaces, 8 (2016) 2306-2317.

[15] S. Luo, J.R. Wiegand, B. Kazanowska, C.M. Doherty, K. Konstas, A.J. Hill, R. Guo, Finely tuning the free volume architecture in iptycene-containing polyimides for highly selective and fast hydrogen transport, Macromolecules, 49 (2016) 3395-3405.

[16] Y.H. Kim, H.S. Kim, S.K. Kwon, Synthesis and characterization of highly soluble and oxygen permeable new polyimides based on twisted biphenyl dianhydride and spirobifluorene diamine, Macromolecules, 38 (2005) 7950-7956.

[17] X. Ma, O. Salinas, E. Litwiller, I. Pinnau, Novel spirobifluorene- and dibromospirobifluorene-based polyimides of intrinsic microporosity for gas separation applications, Macromolecules, 46 (2013) 9618-9624.

[18] J. Weber, O. Su, M. Antonietti, A. Thomas, Exploring polymers of intrinsic microporosity-microporous, soluble polyamide and polyimide, Macromol. Rapid Commun., 28 (2007) 1871-1876.

[19] H. Tong, C. Hu, S. Yang, Y. Ma, H. Guo, L. Fan, Preparation of fluorinated polyimides with bulky structure and their gas separation performance correlated with microstructure, Polymer, 69 (2015) 138-147.

[20] B.S. Ghanem, N.B. McKeown, P.M. Budd, J.D. Selbie, D. Fritsch, High-performance membranes from polyimides with intrinsic microporosity, Adv. Mater., 20 (2008) 2766-2771. [21] B.S. Ghanem, N.B. McKeown, P.M. Budd, N.M. Al-Harbi, D. Fritsch, K. Heinrich, L. Starannikova, A. Tokarev, Y. Yampolskii, Synthesis, characterization, and gas permeation properties of a novel group of polymers with intrinsic microporosity: PIM-polyimides, Macromolecules, 42 (2009) 7881-7888.

[22] Y. Rogan, R. Malpass-Evans, M. Carta, M. Lee, J.C. Jansen, P. Bernardo, G. Clarizia, E. Tocci, K. Friess, M. Lanc, N.B. McKeown, A highly permeable polyimide with enhanced selectivity for membrane gas separations, J. Mater. Chem. A, 2 (2014) 4874-4877.

[23] R. Swaidan, M. Al-Saeedi, B. Ghanem, E. Litwiller, I. Pinnau, Rational design of intrinsically ultramicroporous polyimides containing bridgehead-substituted triptycene for highly selective and permeable gas separation membranes, Macromolecules, 47 (2014) 5104-5114.

[24] Y. Zhuang, J.G. Seong, Y.S. Do, H.J. Jo, Z. Cui, J. Lee, Y.M. Lee, M.D. Guiver, 
Intrinsically microporous soluble polyimides incorporating Tröger's base for membrane gas separation, Macromolecules, 47 (2014) 3254-3262.

[25] Z. Wang, D. Wang, J. Jin, Microporous polyimides with rationally designed chain structure achieving high performance for gas separation, Macromolecules, 47 (2014) $7477-7483$

[26] S. Luo, Q. Liu, B. Zhang, J.R. Wiegand, B.D. Freeman, R. Guo, Pentiptycene-based polyimides with hierarchically controlled molecular cavity architecture for efficient membrane gas separation, J. Membr. Sci., 480 (2015) 20-30.

[27] Y. Yampolskii, V. Shantarovich, Materials science of membranes for gas and vapor separation, John Wiley \& Sons Ltd, Chichester, 2006.

[28] S.J. Tao, Positronium annihilation in molecular substances, J. Chem. Phys., 56 (1972) 5499-5510.

[29] M. Eldrup, D. Lightbody, J.N. Sherwood, The temperature-dependence of positron lifetimes in solid pivalic acid, Chem. Phys., 63 (1981) 51-58.

[30] C. Pascual-Izarra, A.W. Dong, S.J. Pas, A.J. Hill, B.J. Boyd, C.J. Drummond, Advanced fitting algorithms for analysing positron annihilation lifetime spectra, J. Nucl. Instrum. Meth. A, 603 (2009) 456-466.

[31] H. Lin, B.D. Freeman, Permeation and diffusion, in: H. Czichos, T. Saito, L. Smith (Eds.) Springer Handbook of Material Measurement Methods, Springer, New York, 2006, pp. 371-387.

[32] W.J. Fang, L.L. Zhang, J.W. Jiang, Gas permeation and separation in functionalized polymers of intrinsic microporosity: A combination of molecular simulations and AB initio calculations, J. Phys. Chem. C, 115 (2011) 14123-14130.

[33] X. Ma, R. Swaidan, Y. Belmabkhout, Y. Zhu, E. Litwiller, M. Jouiad, I. Pinnau, Y. Han, Synthesis and gas transport properties of hydroxyl-functionalized polyimides with intrinsic microporosity, Macromolecules, 45 (2012) 3841-3849.

[34] Y.C. Wang, S.H. Huang, C.C. Huc, C.L. Li, K.R. Lee, D.J. Liaw, J.Y. Lai, Sorption and transport properties of gases in aromatic polyimide membranes, J. Membr. Sci., 248 (2005) $15-25$.

[35] Y.J. Cho, H.B. Park, High performance polyimide with high internal free volume 
elements, Macromol. Rapid Commun., 32 (2011) 579-586.

[36] R. Swaidan, B. Ghanem, M. Al-Saeedi, E. Litwiller, I. Pinnau, Role of intrachain rigidity in the plasticization of intrinsically microporous triptycene-based polyimide membranes in mixed-gas $\mathrm{CO}_{2} / \mathrm{CH}_{4}$ separations, Macromolecules, 47 (2014) 7453-7462.

[37] S.H. Han, N. Misdan, S. Kim, C.M. Doherty, A.J. Hill, Y.M. Lee, Thermally rearranged (TR) polybenzoxazole: Effects of diverse imidization routes on physical properties and gas transport behaviors, Macromolecules, 43 (2010) 7657-7667.

[38] G. Dlubek, R. Buchhold, C. Hubner, A. Nakladal, K. Sahre, Local free volumes in boron-bombarded kapton polyimide: A positron lifetime study, J. Polym. Sci. Part B: Polym. Phys., 37 (1999) 2539-2543.

[39] C.L. Staiger, S.J. Pas, A.J. Hill, C.J. Cornelius, Gas separation, free volume distribution, and physical aging of a highly microporous spirobisindane polymer, Chem. Mater., 20 (2008) 2606-2608.

[40] P.C. Hiemenz, T.P. Lodge, Polymer chemistry $\left(2^{\text {nd }}\right.$ edition), Taylor \& Francis, Florida: CRC press, 2007.

[41] M.D. Guiver, Y.M. Lee, Polymer rigidity improves microporous membranes, Science, 339 (2013) 284-285.

[42] G. Maier, Gas separation by polymer membranes: beyond the border, Angew. Chem. Int. Edit., 52 (2013) 4982-4984.

[43] W.J. Koros, G.K. Fleming, S.M. Jordan, T.H. Kim, H.H. Hoehn, Polymeric membrane materials for solution-diffusion based permeation separations, Prog. Polym. Sci., 13 (1988) 339-401.

[44] T.C. Merkel, V. Bondar, K. Nagai, B.D. Freeman, Sorption and transport of hydrocarbon and perfluorocarbon gases in poly(1-trimethylsilyl-1-propyne), J. Polym. Sci. Part B: Polym. Phys., 38 (2000) 273-296.

[45] A.C. Puleo, D.R. Paul, S.S. Kelley, The effect of degree of acetylation on gas sorption and transport behavior in cellulose-acetate, J. Membr. Sci., 47 (1989) 301-332.

[46] K. Tanaka, M. Okano, H. Toshino, H. Kita, K.I. Okamoto, Effect of methyl substituents on permeability and permselectivity of gases in polyimides prepared from methyl-substituted phenylenediamines, J. Polym. Sci. Part B: Polym. Phys., 30 (1992) 907-914. 
[47] S. Thomas, I. Pinnau, N. Du, M.D. Guiver, Pure- and mixed-gas permeation properties of a microporous spirobisindane-based ladder polymer (PIM-1), J. Membr. Sci., 333 (2009) 125-131.

[48] P.M. Budd, K.J. Msayib, C.E. Tattershall, B.S. Ghanem, K.J. Reynolds, N.B. McKeown, D. Fritsch, Gas separation membranes from polymers of intrinsic microporosity, J. Membr. Sci., 251 (2005) 263-269.

[49] R. Swaidan, B. Ghanem, E. Litwiller, I. Pinnau, Physical aging, plasticization and their effects on gas permeation in "rigid" polymers of intrinsic microporosity, Macromolecules, 48 (2015) 6553-6561. 
Graphical Abstract

\section{Graphic Abstract}
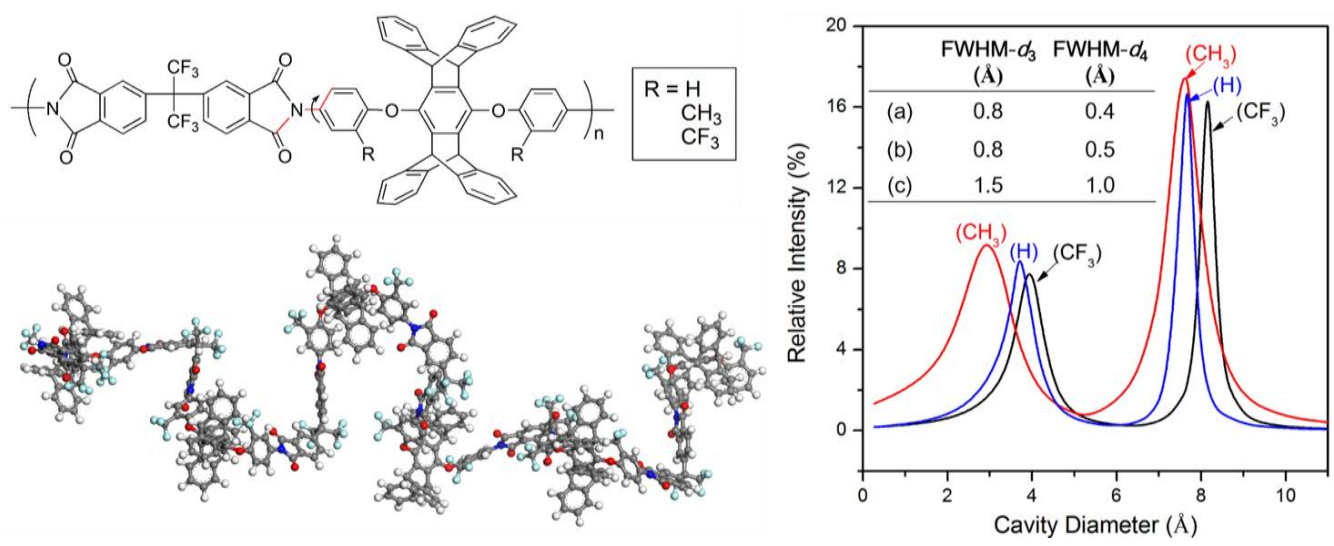